\title{
Demyelinating sentinel lesion preceding a primary central nervous system lymphoma
}

Lesão desmielinizante sentinela precedendo linfoma primário do sistema nervoso central Flávia SPRENGER', Thais BIANCO'1, Bernardo Corrêa de Almeida TEIXEIRA'

A 29-year-old man presented with tonic-clonic seizures. Initial MRI showed a lesion centered on the white matter of the left frontal lobe, with restricted diffusion and contrast enhancement on its margins and low rCBV and hypometabolismon PET-CT, suggestive of a tumefactive demyelination lesion (Figure 1). Patient underwent surgical biopsy, with no signs of malignancy (Figure 2). Two months later, control MRI showed a new lesion on the brainstem, with solid enhancement and hypermetabolism on PET-CT, compatible with lymphoma (Figures 3 and 4).

Demyelinating sentinel lesions preceding CNS lymphomas are a rare entity and its pathophysiology is not fully understood ${ }^{1,2}$.

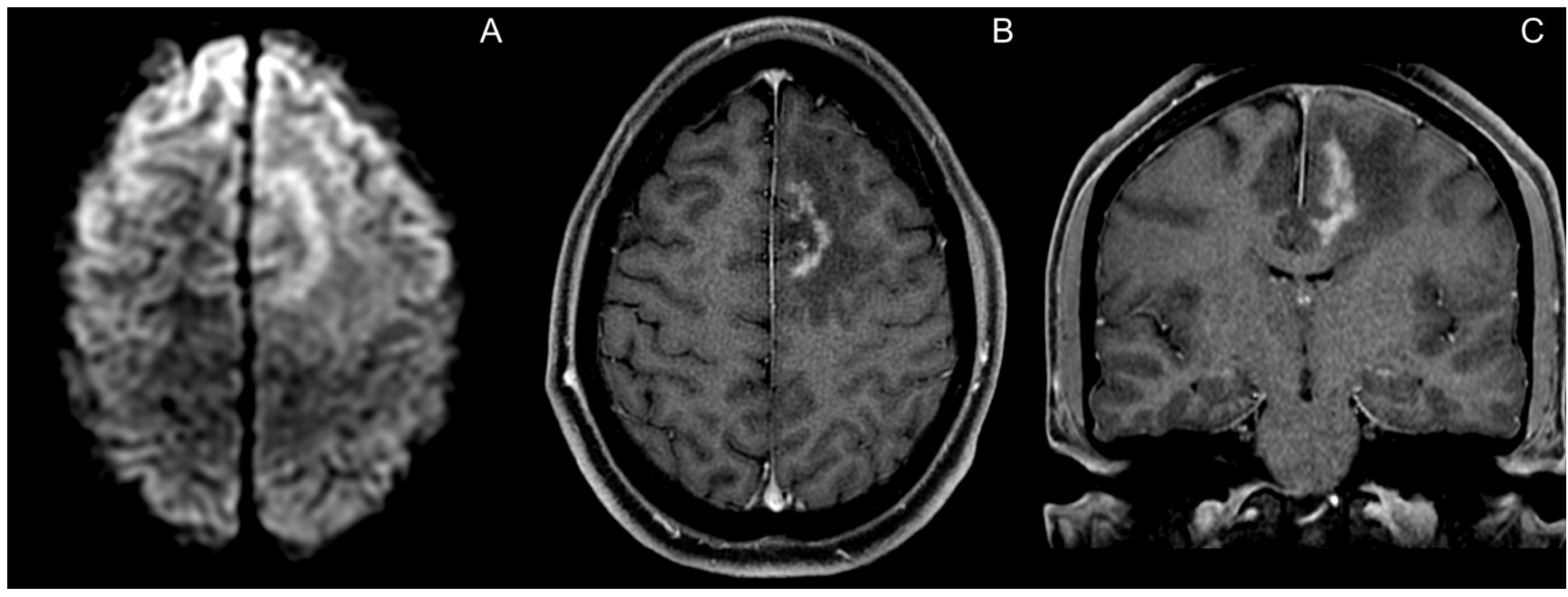

Figure 1. A: Axial diffusion weighted imaging (DWI), showing a left frontal lesion with restricted diffusion on the lesion's free margin, oriented towards the white matter, suggestive of demyelinating nature. B: Axial post-gadolinium T1, showing contrast enhancement on the lesions free margin. C: Coronal post-gadolinium T1 shows the left frontal lesion, insinuating towards the corpus callosum, but with no frank signs of invasion. Notice the spared brainstem.

'Universidade Federal do Paraná, Hospital de Clínicas, Departamento de Radiologia, Curitiba PR, Brazil. FS (iD https://orcid.org/0000-0002-1631-3517; TB (D) https://orcid.org/0000-0002-9861-0645; BCAT (iD) https://orcid.org/0000-0003-4769-6562 Correspondence: Flávia Sprenger; Email: flaviasprenger@gmail.com. 


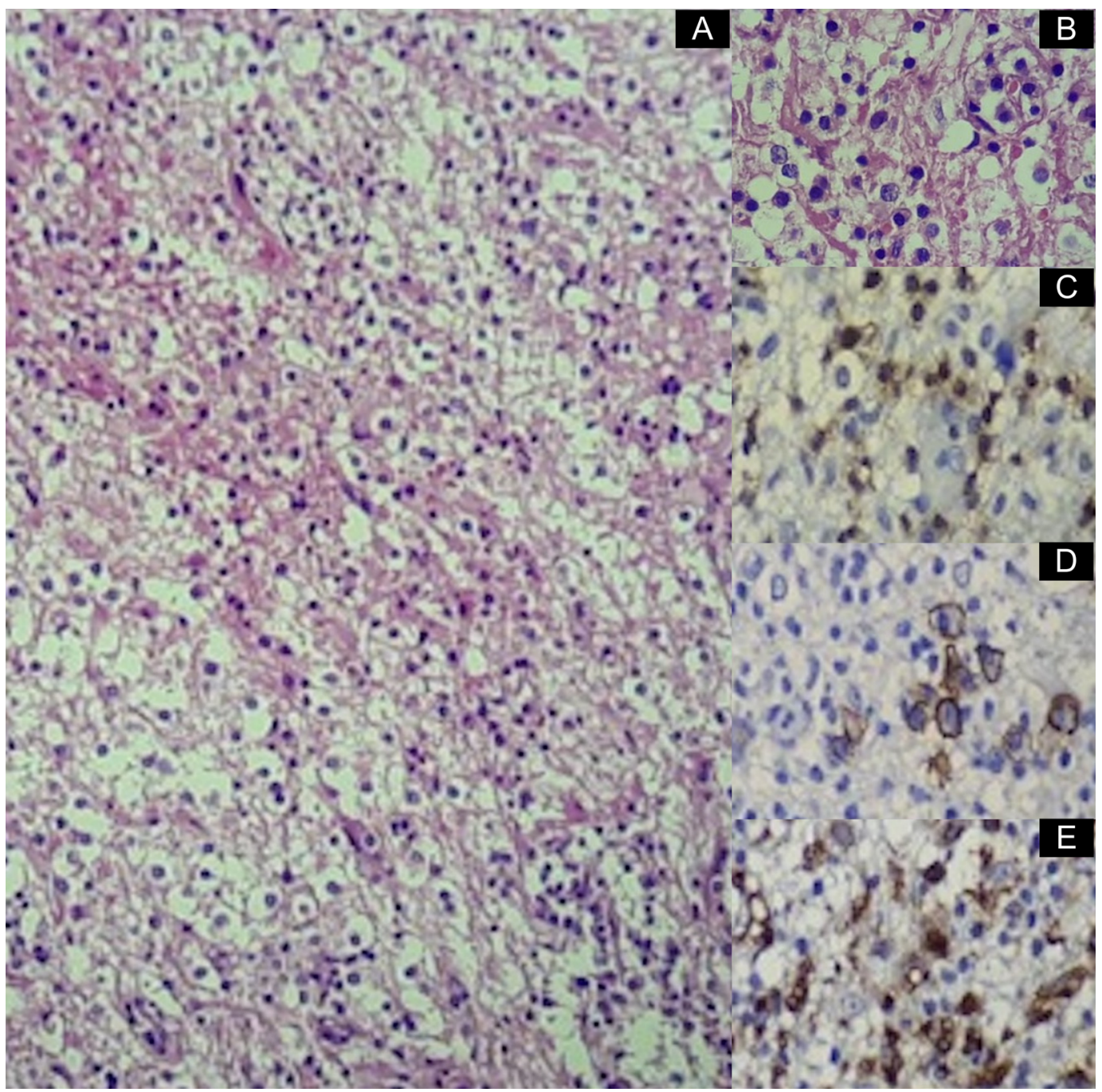

Figure 2. Histopathological findings from surgical biopsy. A: Hematoxicilin-eosin 100x, amplified on B, shows a diffuse inflammatory infiltrate composed by T-lymphocytes, confirmed by immunohistochemistry for CD3 marker on C, plasmacytes (CD138 on D) and foamy macrophages (CD68 on E). The sample was negative for malignancy and markers for B cells were negative (not shown).

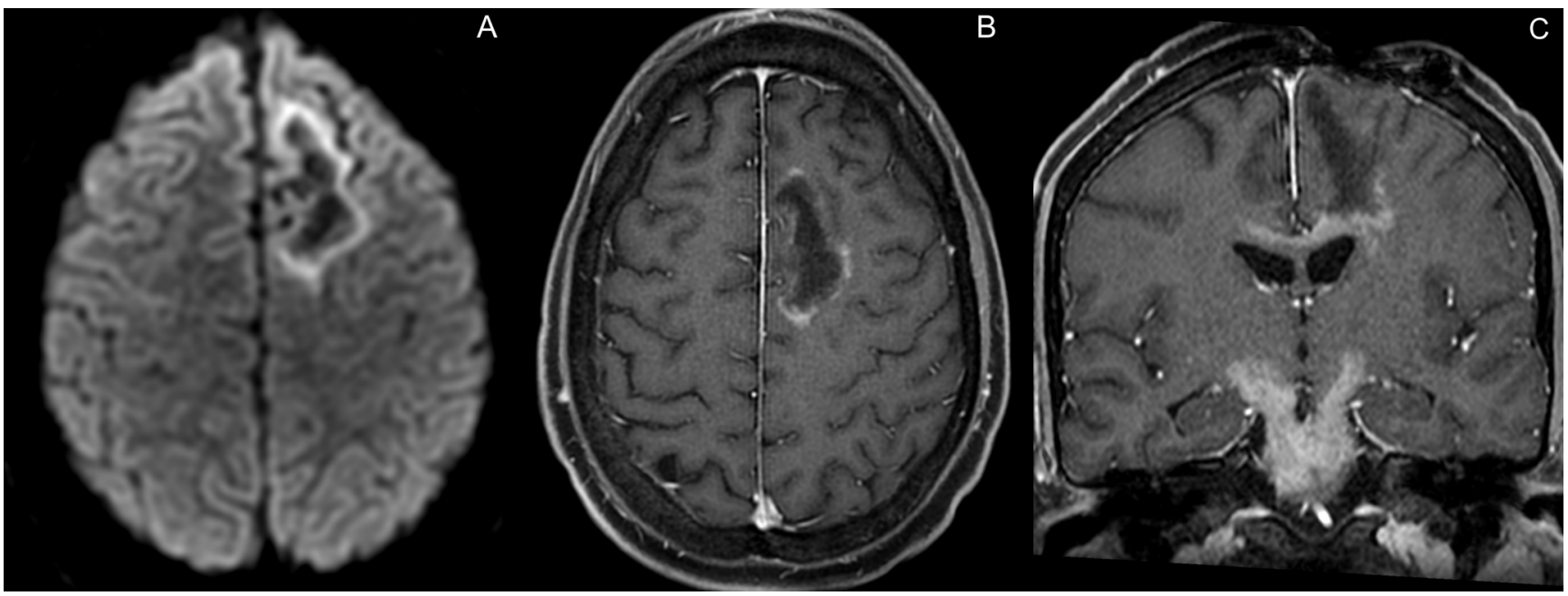

Figure 3. Control MRI two months later, demonstrates persistent restricted diffusion (A), but less enhancement of the left frontal lesion (B). C (coronal post-gadolinium T1): Its caudal aspect extends and invades the corpus callosum. Notice the development of a new and solid-enhancing lesion on the brainstem, extending along the cerebral peduncles and the postoperative changes on the left frontal lobe. 


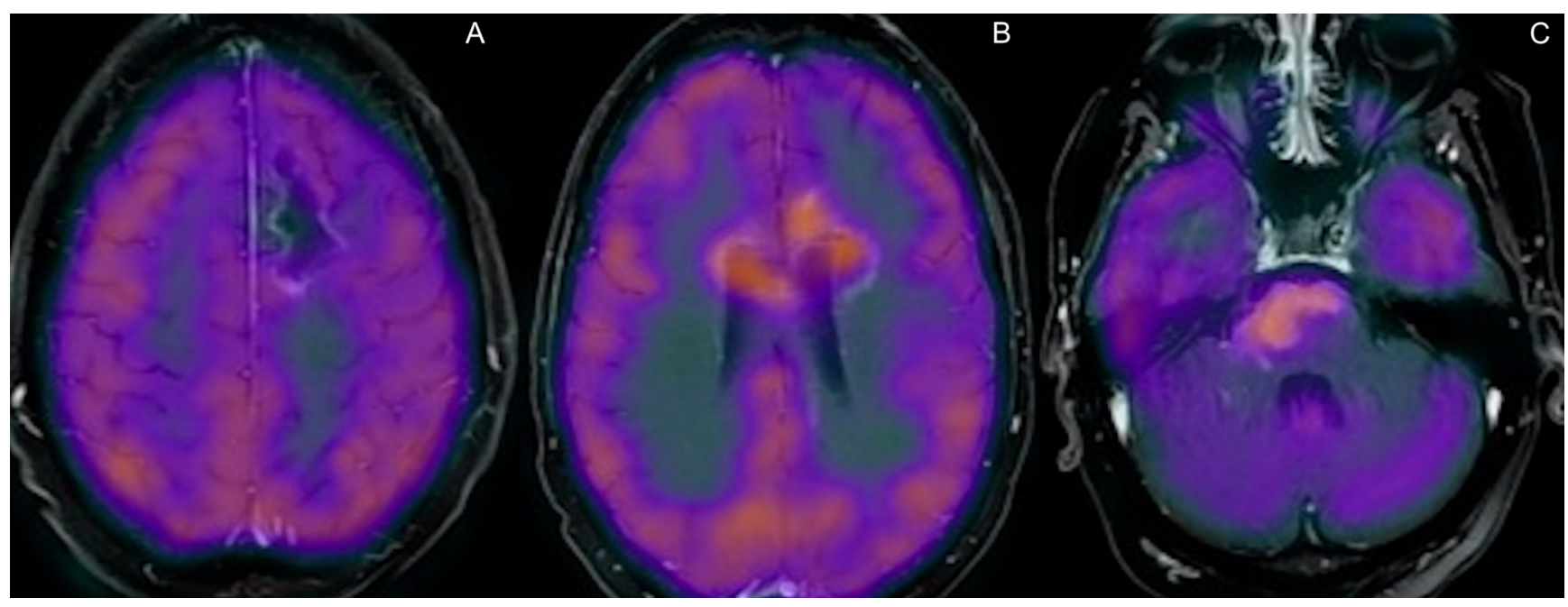

Figure 4. PET-CT and MRI fusion, showing the hypometabolic behavior of the original left frontal lesion (A), in contrast with hypermetabolism on the corpus callosum (B) and brainstem (C) lesions, inferring different etiologies.

\section{References}

1. Kvarta MD, Sharma D, Castellani RJ, Morales RE, Reich SG, Kimball AS, et al. Demyelination as a harbinger of lymphoma: a case report and review of primary central nervous system lymphoma preceded by multifocal sentinel demyelination. BMC Neurol. 2016 May 21;16:72. https://doi.org/10.1186/s12883-016-0596-1
2. Kuhlmann T, Schröter A, Dechent P, Weber F, Rustenbeck HH, Füzesi $L$, et al. Diagnosis of a multifocal B cell lymphoma with preceding demyelinating central nervous system lesions by single voxel proton MR spectroscopy. J Neurol Neurosurg Psychiatry. 2001 Feb 1;70(2):259-62. https://doi.org/10.1136/jnnp.70.2.259 